\title{
Altered function of the left ventricle and clinical significance of heart-type fatty acid-binding protein in cardiac dysfunction among patients with sepsis
}

\author{
GUOPENG WENG $^{1}$, PEIGANG TIAN ${ }^{1}$, XIAOJUN YAN $^{2}$ and QINGHONG CHENG $^{1}$ \\ ${ }^{1}$ Second Department of Critical Care Medicine, The First Affiliated Hospital of Medical College, \\ Shihezi University; ${ }^{2}$ Department of Cardiac Echocardiography, The First Affiliated Hospital \\ of Medical College, Shihezi University, Shihezi, Xinjiang 832002, P.R. China
}

Received July 23, 2019; Accepted March 25, 2020

DOI: $10.3892 /$ etm.2020.9186

\begin{abstract}
The present study aimed to determine the clinical significance of heart-type fatty acid-binding protein (H-FABP) in patients with sepsis-induced cardiac dysfunction. A total of 30 healthy subjects served as the control group and 80 patients with sepsis were recruited for the present single-center prospective observational study for the final analysis. Among these patients, 50 developed cardiac dysfunction, while no cardiac dysfunction was detected in the remaining 30 patients. Echocardiography was performed on days 1, 3, 7 and 10 of hospitalization. Routine blood biochemistry, serum H-FABP, $\mathrm{N}$-terminal pro-brain natriuretic peptide (NT-proBNP) and troponin I were also analyzed. Alterations in cardiac biomarkers and echocardiography results were compared between patients with sepsis who did and who did not develop any cardiac dysfunction to determine the time of the occurrence of sepsis-induced cardiac dysfunction. Furthermore, the significance of H-FABP in the prediction of the 28-day mortality rate was evaluated using binary logistic regression analysis for sepsis and receiver operating characteristic (ROC) curve analysis. In addition, the specificity and sensitivity of $\mathrm{H}-\mathrm{FABP}$ in the prediction of sepsis-induced cardiac dysfunction were verified using ROC curve analysis. For patients with cardiac dysfunction, the levels of cardiac output (CO), stroke volume (SV), mitral early diastolic peak velocity to mitral atrial systolic peak velocity ratio (E/A) and left ventricle ejection fraction (LVEF) were relatively decreased, while the levels of H-FABP and NT-proBNP were markedly increased compared with patients with sepsis and without cardiac dysfunction. $\mathrm{CO}$
\end{abstract}

Correspondence to: Dr Qinghong Cheng, Second Department of Critical Care Medicine, The First Affiliated Hospital of Medical College, Shihezi University, 107 Beier Road, Shihezi, Xinjiang 832002, P.R. China

E-mail: xunfeicheng@aliyun.com

Key words: sepsis, cardiac dysfunction, echocardiography, cardiac biomarkers, heart-type fatty acid-binding protein and SV initially increased and subsequently decreased. EF was elevated, and E/A initially decreased and subsequently increased. Furthermore, H-FABP and NT-proBNP decreased in sepsis patients with cardiac dysfunction. The results of the ROC curve and binary logistic regression analyses suggest that H-FABP was associated with the 28-day prognosis for patients with sepsis. An H-FABP level of $>35.7 \mathrm{ng} / \mathrm{ml}$ was able to predict the 28-day mortality for patients with sepsis, with an area under the curve (AUC) of 0.680 . Furthermore, $>30.3 \mathrm{ng} / \mathrm{ml}$ was the threshold for the prediction of sepsis-induced cardiac dysfunction, and the sensitivity and specificity were 76.27 and $61.76 \%$, respectively, with an AUC of 0.673. In summary, patients with sepsis had an increased risk of cardiac insufficiency on days 7-10 of hospitalization. In addition, H-FABP may serve as an indicator to predict the prognosis of patients with sepsis in the short term, which has a certain significance in the diagnosis of sepsis-induced cardiac dysfunction.

\section{Introduction}

Sepsis is a type of organ dysfunction that poses a threat to human life and is induced by the imbalanced response of the host to confirmed or suspected infection (1). Septic shock, which is a subtype of sepsis, has been recognized as a specific process of sepsis development (2). There are millions of new sepsis patients every year worldwide. Among these patients, $\sim 1 / 4$ die $(1,3)$. Sepsis is characterized by high cost of medical treatment, high mortality and high morbidity, and it frequently results in organ dysfunction. Specifically, the heart is the organ frequently affected by sepsis. Cardiac dysfunction induced by sepsis is the leading cause of death (4). Of note, cardiac dysfunction usually occurs in sepsis patients, which gives rise to reduced systemic perfusion of the organ and in turn enhances disease progression $(5,6)$. For patients who die due to septic shock and severe sepsis, most succumb due to damage to the cardiovascular system, and $40 \%$ of patients who survive sepsis develop myocardial damage (7). Furthermore, these conditions worsen when cardiac dysfunction occurs earlier, along with a higher death rate (8). Thus, it would be favorable to accurately identify sepsis-induced cardiac dysfunction early for improving the prognosis of these patients. 
Transthoracic echocardiography (TTE) has become a vital approach to evaluate the cardiac function of patients in the clinic. In addition, it is the leading technique for the diagnosis of cardiac insufficiency $(9,10)$. According to previous studies, a left ventricular ejection fraction (LVEF) of $<50 \%$ may be utilized to determine sepsis-induced cardiac dysfunction $(11,12)$. However, other investigators have discovered that $\sim 1 / 2$ of patients with sepsis and cardiac dysfunction exhibit a normal ejection fraction based on an LVEF of $\leq 50 \%$ (6). At present, N-terminal pro-brain natriuretic peptide (NT-proBNP) is used as the 'gold standard' for the diagnosis of heart failure (HF) in adults (13). The serum level of NT-proBNP is altered with changes in cardiac function. As suggested by previous studies, for patients with sepsis, cardiac insufficiency is a type of reversible functional alteration $(14,15)$. Thus, NT-proBNP may serve as an indicator for the differentiation of patients with normal LVEF from patients with sepsis. However, apart from cardiac function, elevated NT-proBNP levels with sepsis are impacted by various factors in such patients. Sepsis-induced cardiac dysfunction is generally diagnosed on the basis of clinical signs, symptoms and assisted examination, combined with LVEF or NT-proBNP. As a marker for myocardial damage, heart-type fatty acid-binding protein (H-FABP) has recently become a research hotspot. H-FABP is better than conventional cardiac markers for the early diagnosis of acute myocardial damage due to higher sensitivity and specificity $(16,17)$. Furthermore, H-FABP has a close correlation with the severity of sepsis and may serve as a candidate cardiac marker for the diagnosis of sepsis-induced cardiac dysfunction (17-19). In the present study, TTE, as well as the dynamic changes of H-FABP and NT-proBNP, were explored in patients with sepsis to determine the precise time of the occurrence of sepsis-induced cardiac dysfunction and the clinical significance of H-FABP for diagnosis.

\section{Materials and methods}

Study subjects. Between October 2016 and February 2018, a total of 94 inpatients with sepsis aged $\geq 18$ years were recruited from the intensive care unit (ICU) of the First Affiliated Hospital of Shihezi University (Shihezi, China) in accordance with Sepsis 3.0 (20). Among these patients, 80 were finally enrolled in the present study as the sepsis group. A total of 30 healthy volunteers who had normal physical examinations were included as the control group. None of the patients screened had arrhythmia, organic heart disease (HD), recent cardiovascular or cerebrovascular diseases or chronic renal insufficiency. In addition, none of the enrolled patients were hospitalized for $<3$ days for any different reasons. For these patients, organic HDs referred to the following diseases: Ischemic cardiomyopathy, old myocardial infarction (MI) and acute MI; primary cardiomyopathy (including restrictive, hypertrophic and dilated cardiomyopathy); metabolic cardiomyopathy (e.g., alcoholic, hyperthyroid, anemic and uremic cardiomyopathy); congenital HD; valvular HD; and infective endocarditis and myocarditis (Fig. 1).

Diagnostic standards. The diagnostic standards for sepsis were as follows: i) Patients at the ICU with suspected or confirmed sepsis infection with a Sequential Organ Failure Assessment
(SOFA) score of $\geq 2$ points were diagnosed as having sepsis (1) (Table SI); and ii) in patients without suspected or confirmed ICU infection, the quick SOFA score (including a systolic blood pressure of $\leq 100 \mathrm{mmHg}$, an altered conscious state and a respiratory rate of $\geq 22$ beats/min) was assessed and sepsis was diagnosed when the patient was positive for at least two items.

The diagnostic standards for cardiac dysfunction were as follows: By an experienced clinician, cardiac insufficiency was determined according to the imaging data and the signs and clinical symptoms of patients combined with the LVEF or NT-proBNP values. As recommended in the 2017 Guidelines for Heart Failure Management by the American Heart Association (AHA), American College of Cardiology (ACC) and Heart Failure Society Of America (HFSA) (13), acute $\mathrm{HF}$ was diagnosed in the case of NT-pro BNP $>1,800 \mathrm{pg} / \mathrm{ml}$ ( $>75$ years), NT-pro BNP $>900$ pg/ml (50-75 years) and NT-pro $\mathrm{BNP}>450 \mathrm{pg} / \mathrm{ml}$ ( $<50$ years); acute HF was excluded when NT-pro BNP was $<300 \mathrm{pg} / \mathrm{ml}$; chronic HF was excluded when NT-pro BNP was $<125 \mathrm{pg} / \mathrm{ml}$; and systemic dysfunction was suspected when LVEF was $<50 \%$. According to the 2016 American Society of Echocardiography (ASE) and the European Association of Cardiovascular Imaging (EACVI) guidelines for diastolic function of the left ventricle examined by echocardiography, an E/A of $<0.8$ was considered as an indicator of diastolic dysfunction in the left ventricle (21).

Variables in the study. The baseline patient characteristics, including gender and age, were recorded. At the same time, the 24 small-order SOFA and the Acute Physiology and Chronic Health Evaluation II (APACHE II) scores of patients with sepsis were determined upon admission (22), according to the results of the laboratory tests and the clinical symptoms. The SOFA and APACHE II scores were recorded.

These sepsis patients were hospitalized at the Department of Clinical Laboratory of the First Affiliated Hospital of Shihezi University (Shihezi, China) for 1, 3, 7 and 10 days. Healthy subjects were assigned to the control group and their relevant information was collected on the day of the physical examination. A CELL-DYN Ruby was utilized to measure the neutrophil and white blood cell (WBC) percentages. Furthermore, the level of creatine kinase-MB (CK-MB) was determined using the 2700 automatic biochemical analyzer (Olympus Corporation), and the level of cardiac troponin I (cTnI) was measured by the automatic enzyme immunoassay device AIA-360 (Tosoh Corporation) using a fluorescence magnetic microparticle enzyme technique. In addition, the NT-proBNP and procalcitonin (PCT) contents were measured using the Roche Cobas 8000 by electrochemiluminescence. Next, cubital venous samples were collected at specific time-points after fasting. ELISA was performed with the ELX800 microplate reader at the Key Laboratory of Xinjiang Endemic and Ethnic Diseases (Shihezi, China). H-FABP was measured using the H-FABP test kit (cat. no. E-EL-H1431c; Elabscience), according to the manufacturer's protocol. To obtain the results for the H-FABP test, the optical density value at $450 \mathrm{~nm}$ was determined using the ELX800 microplate reader (Bioelisa; Biokit). Finally, the serum levels of H-FABP were acquired.

Heart ultrasound was performed using the Philips IE33 (Philips Healthcare) by one experienced sonographer who was trained at TTE, and the following indicators were recorded: 


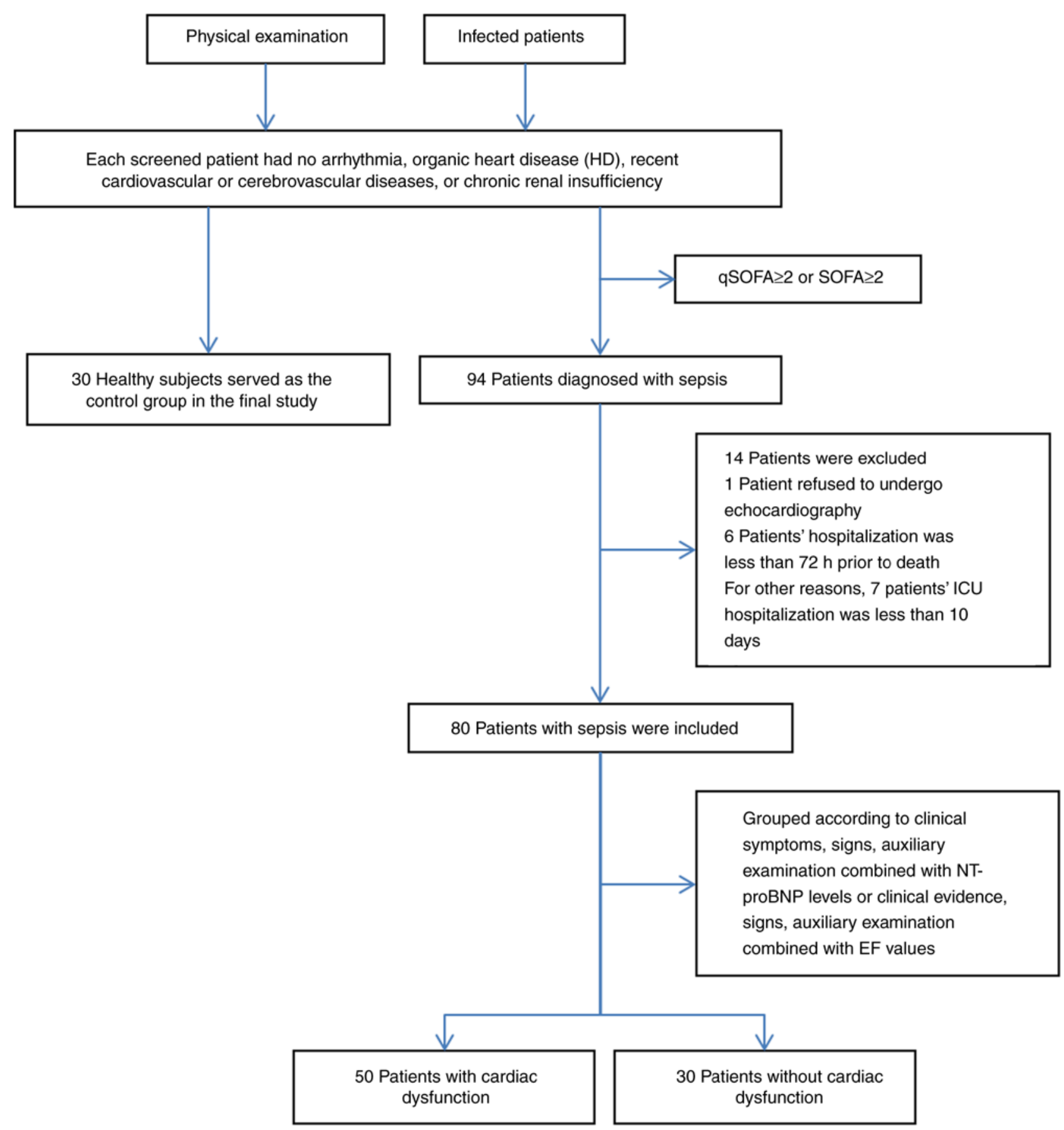

Figure 1. Flowchart of the screening process. ICU, intensive care unit; EF, ejection fraction; qSOFA, quick Sequential Organ Failure Assessment; NT-pro BNP, $\mathrm{N}$-terminal pro-brain natriuretic peptide.

End-systolic volume (ESV), end-diastolic volume (EDV), LVEF, cardiac output (CO), stroke volume (SV), mitral atrial systolic peak velocity (A), mitral early diastolic peak velocity (E), E/A ratio (E/A), diastolic pulmonary venous peak velocity (D), systolic pulmonary venous peak velocity (S) and the S/D ratio $(\mathrm{S} / \mathrm{D})$.

Clinical evaluation. A total of 80 patients with sepsis were monitored for a period of 28 days following enrollment. In the present study, the endpoints were deemed survival and death, and these were examined on days 1, 3, 7, 10 and 28 during the study process.
Statistical analysis. SPSS 20.0 (IBM Corp.) was utilized for all statistical analyses. The measurement values are presented as the mean \pm standard deviation, while abnormally distributed values are presented as the median (interquartile range). Normality distribution of the variables was tested using the 1-sample Kolmogorov-Smirnov test. Continuous variables were compared using Student's t-test or the Mann-Whitney $\mathrm{U}$ test between groups, depending on distribution. Categorical variables were analyzed using the $\chi^{2}$ test. The data were compared between two groups and a t-test was performed in the presence of homogeneous variance in the measurement data, while the Wilcoxon rank-sum test was utilized in the 
Table I. General characteristics of all patients of the present study.

\begin{tabular}{|c|c|c|c|c|}
\hline Variable & Control $(n=30)$ & Sepsis $(n=80)$ & $t / \chi^{2}$ & P-value \\
\hline Sex (male/female) & $14 / 16$ & $51 / 29$ & 3.738 & 0.053 \\
\hline Age (years) & $65.90 \pm 12.17$ & $71.11 \pm 14.24$ & 1.775 & 0.079 \\
\hline APACHEII score & $4.00 \pm 1.53$ & $15.19 \pm 5.95$ & 10.123 & $<0.001$ \\
\hline SOFA score & - & $5.54 \pm 3.62$ & - & - \\
\hline
\end{tabular}

Values are expressed as the mean \pm standard deviation or n. APACHE, Acute Physiology and Chronic Health Evaluation; SOFA, Sequential Organ Failure Assessment.

Table II. General characteristics of patients with sepsis by cardiac dysfunction in the present study.

\begin{tabular}{lccc}
\hline Variables & $\begin{array}{c}\text { Sepsis with cardiac } \\
\text { dysfunction (n=50) }\end{array}$ & $\begin{array}{c}\text { Sepsis without cardiac } \\
\text { dysfunction (n=30) }\end{array}$ & $\begin{array}{c}\text { P-value } \\
\text { t/ } \chi^{2}\end{array}$ \\
\hline Age (years) & $71.52 \pm 15.496$ & $70.43 \pm 12.091$ & 0.328 \\
Sex (male/female) & $29 / 21$ & $8 / 22$ & 1.908 \\
APACHEII score (1st day ICU) & $15.98 \pm 6.57$ & $13.83 \pm 4.56$ & 1.575 \\
SOFA score (1st day ICU) & $6.12 \pm 4.09$ & $4.57 \pm 2.45$ & 2.126 \\
28-day mortality & $13(26.0)$ & $3(10.0)$ & 1.870 \\
Source of infection & & & 5.269 \\
Abdominal & 8 & 3 & 0.119 \\
Pulmonary & 35 & 25 & 0.384 \\
Urinary & 3 & 0 & 1 \\
Central nervous system & 0 & 0 & \\
Blood & 1 & 1 & \\
Skin or soft tissue & 3 & & \\
\hline
\end{tabular}

Values are expressed as the mean \pm standard deviation or $\mathrm{n}(\%)$. APACHE, Acute Physiology and Chronic Health Evaluation; SOFA, Sequential Organ Failure Assessment; ICU, intensive care unit.

case of heterogeneous variance. For data with heterogeneous variance, the Kruskal-Wallis test was used for comparison of multiple groups, followed by Dunn's post-hoc test, while the Mann-Whitney U-test was used for comparison of two groups. Categorical data were examined by the $\chi^{2}$ test. Repeated-measures analysis of variance was employed to analyze the repeated measurement data. Spearman's rank correlation was applied in the correlation analysis. Furthermore, binary logistic regression was used to assess cardiac dysfunction and determine the 28-day death rate. At the same time, the best threshold was confirmed using receiver operating characteristic (ROC) curve analysis. $\mathrm{P}<0.05$ was considered to indicate statistical significance.

\section{Results}

General patient features. There were no significant differences in age or gender between the control group and the sepsis group. The APACHE II scores of patients in the sepsis group were significantly higher than those in the control group (Table I).

The sepsis group was further divided into two groups based on the presence or absence of cardiac insufficiency: The sepsis without cardiac dysfunction group and the sepsis with cardiac dysfunction group. The common features, including age and gender, were not statistically significant between these two groups. In addition, compared with patients with sepsis and normal heart function, the 28-day death rate and APACHE II score were increased in patients with sepsis and cardiac dysfunction, but there was no statistically significant difference $(\mathrm{P}>0.05)$. Compared with patients with no cardiac dysfunction, the SOFA score increased among patients with sepsis-induced cardiac dysfunction $(\mathrm{P}=0.037)$. However, the difference in infection source was not statistically significant between these two groups $(\mathrm{P}=0.384$; Table II).

Laboratory parameters. The WBC, neutrophil ratio (N\%), PCT, NT-proBNP, cTnI and H-FABP of patients in the sepsis group were higher than those of healthy subjects in the control group $(\mathrm{P}<0.05)$ on days $1,3,7$ and 10 . Furthermore, the serum CK-MB was higher than that in the control group on days 1 and $3(\mathrm{P}<0.05)$, but there was no significant difference between groups on days 7 and 10 ( $\mathrm{P}>0.05$; Table III).

The following results were obtained from the repeated-measures analysis of the laboratory test data for 
sepsis with or without cardiac dysfunction in these two groups. The H-FABP, WBC, CK-MB and N\% at various time-points were higher in patients with cardiac dysfunction than in patients without cardiac dysfunction $(\mathrm{P}<0.05)$. Regardless of the time-point, the H-FABP, CK-MB and N\% of patients with sepsis-induced cardiac dysfunction were higher than in those without cardiac dysfunction $(\mathrm{P}<0.05)$; the WBC increased among patients with sepsis-induced cardiac dysfunction, but the difference was not statistically significant (P>0.05), and the WBC, N\%, CK-MB and H-FABP exhibited no significant differences among the different groups and the different time-points $(\mathrm{P}>0.05)$. For various groups and at various time-points, PCT increased in patients with sepsis-induced cardiac dysfunction $(\mathrm{P}<0.05)$, and the differences were significant $(\mathrm{P}<0.05)$. Furthermore, the cTnI levels at various time-points and among various groups increased in patients with sepsis-induced cardiac dysfunction, but the difference was not statistically significant $(P>0.05)$, and no significant difference was detected among the different groups and different time-points $(\mathrm{P}>0.05)$. Furthermore, $\mathrm{PCT}$ exhibited significant differences among the different groups and different time-points $(\mathrm{P}<0.05)$, but the other indicators were not significantly different among the different groups and different time-points ( $\mathrm{P}>0.05$; Table IV). NT-proBNP was increased among patients with sepsis-induced cardiac dysfunction in various groups and at various time-points $(\mathrm{P}<0.001$; Table V).

Echocardiography. According to the echocardiographic indicators of the sepsis group at different time-points, the ultrasound indicators of EDV, SV and EF at days 7 and 10; $\mathrm{CO}$ and $\mathrm{E} / \mathrm{A}$ at day 10; and $\mathrm{E}$ at day 7 in the sepsis group were compared with those in the control group, and the differences were not statistically significant $(P>0.05)$. However, for the other time-points, the differences were statistically significant $(\mathrm{P}<0.05$; Table VI).

According to the repeated-measures analysis of the echocardiography results, the differences in EF, ESV, CO, SV, E/A, A, E, S/D, D and $S$ at various time-points were statistically significant between the sepsis with cardiac dysfunction group and the sepsis without cardiac dysfunction group $(\mathrm{P}<0.05)$. Furthermore, the differences in EF, ESV, CO, SV, D and S were statistically significant between groups, regardless of the time-point $(\mathrm{P}<0.05)$. In addition, there were significant differences among ESV, EDV, D, S, A and S/D at the different time-points and between the different groups $(\mathrm{P}<0.05)$, while none were obtained for $\mathrm{EF}, \mathrm{SV}, \mathrm{E}, \mathrm{CO}$ and $\mathrm{E} / \mathrm{A}(\mathrm{P}>0.05$; Tables VII and VIII).

The trends for ESV, EDV, CO, SV, E/A and EF suggested that ESV and EDV decreased, which was distinct on day 10 among patients with sepsis-induced cardiac dysfunction. These two indicators reached their minimum on day 7 in patients with sepsis and no cardiac dysfunction but increased on day 10. The SV among patients with sepsis-induced cardiac dysfunction reached its maximum on day 7 but decreased on day 10 . The EF gradually increased among patients with sepsis-induced cardiac dysfunction. The EF reached its maximum on day 7 among patients with sepsis and no cardiac dysfunction but decreased to the initial level on day 10 . The $\mathrm{E} / \mathrm{A}$ ratios in the two groups decreased. These levels reached a 
Table IV. Repeated-measures analysis of laboratory indicators of sepsis with or without cardiac dysfunction.

\begin{tabular}{|c|c|c|c|c|c|c|}
\hline Group/day & WBC $\left(\times 10^{9} / 1\right)$ & $\mathrm{N} \%$ & PCT (ng/ml) & cTnI (ng/ml) & CK-MB (U/l) & $\mathrm{H}-\mathrm{FABP}(\mathrm{ng} / \mathrm{ml})$ \\
\hline \multicolumn{7}{|c|}{$\begin{array}{l}\text { Sepsis with cardiac } \\
\text { dysfunction }\end{array}$} \\
\hline 1 & $12.32 \pm 7.12$ & $84.12 \pm 13.94$ & $26.705 \pm 54.08^{\mathrm{a}}$ & $0.515 \pm 1.974$ & $32.84 \pm 36.82^{\mathrm{a}}$ & $41.08 \pm 11.75^{\mathrm{a}}$ \\
\hline 3 & $10.71 \pm 5.10$ & $82.34 \pm 8.08^{\mathrm{a}}$ & $11.54 \pm 26.50$ & $0.533 \pm 1.327$ & $22.98 \pm 16.81$ & $38.17 \pm 10.32^{\mathrm{a}}$ \\
\hline 7 & $9.37 \pm 4.68$ & $79.00 \pm 8.89^{a}$ & $1.97 \pm 4.47$ & $0.125 \pm 0.207$ & $16.11 \pm 7.80$ & $36.21 \pm 10.32^{\mathrm{a}}$ \\
\hline 10 & $9.80 \pm 4.39$ & $76.11 \pm 10.76$ & $1.13 \pm 2.82$ & $0.124 \pm 0.240$ & $18.42 \pm 16.08$ & $32.84 \pm 14.29^{\mathrm{a}}$ \\
\hline \multicolumn{7}{|c|}{$\begin{array}{l}\text { Sepsis without cardiac } \\
\text { dysfunction }\end{array}$} \\
\hline 1 & $10.90 \pm 6.34$ & $80.62 \pm 10.39$ & $5.40 \pm 14.40$ & $0.219 \pm 0.429$ & $17.77 \pm 8.01$ & $34.02 \pm 17.27$ \\
\hline 3 & $8.52 \pm 4.17$ & $76.96 \pm 10.85$ & $1.89 \pm 4.58$ & $0.191 \pm 0.379$ & $16.93 \pm 17.32$ & $30.97 \pm 12.33$ \\
\hline 7 & $8.44 \pm 3.98$ & $71.73 \pm 11.29$ & $0.70 \pm 1.25$ & $0.062 \pm 0.141$ & $14.43 \pm 4.14$ & $29.78 \pm 13.21$ \\
\hline 10 & $8.70 \pm 2.96$ & $72.65 \pm 11.16$ & $0.467 \pm 1.05$ & $0.075 \pm 0.199$ & $13.05 \pm 3.68$ & $21.54 \pm 11.40$ \\
\hline \multicolumn{7}{|c|}{$\begin{array}{l}\text { Statistical } \\
\text { comparison: Time }\end{array}$} \\
\hline $\mathrm{F}$ & 7.253 & 15.306 & 8.736 & 2.775 & 6.580 & 11.584 \\
\hline P-value & 0.002 & $<0.001$ & 0.003 & 0.091 & 0.003 & $<0.001$ \\
\hline \multicolumn{7}{|c|}{ Statistical comparison: } \\
\hline \multicolumn{7}{|c|}{ Time $\mathrm{x}$ group } \\
\hline $\mathrm{F}$ & 10.110 & 0.880 & 4.049 & 0.680 & 2.449 & 0.758 \\
\hline P-value & 0.651 & 0.432 & 0.042 & 0.440 & 0.097 & 0.501 \\
\hline \multirow{2}{*}{\multicolumn{7}{|c|}{$\begin{array}{l}\text { Statistical comparison: } \\
\text { Group }\end{array}$}} \\
\hline & & & & & & \\
\hline $\mathrm{F}$ & 2.512 & 6.973 & 4.639 & 1.444 & 5.868 & 17.303 \\
\hline P-value & 0.117 & 0.010 & 0.034 & 0.233 & 0.018 & $<0.001$ \\
\hline
\end{tabular}

${ }^{\mathrm{a}} \mathrm{P}<0.05$ vs. group with sepsis without cardiac dysfunction at the same time-point. Statistical comparisons for Time: Regardless of grouping, comparison of different measurement times; Time x Group: Comparison of time and group interaction; Group: Regardless of measurement time, comparison between different groups. 1,3,7 and 10 correspond with the duration of hospitalization in days. WBC, white blood cells; N\%, neutrophil ratio; PCT, procalcitonin; cTnI, cardiac troponin I; H-FABP, heart-type fatty acid-binding protein.

minimum on day 7 and were further elevated on day 10. The E/A among patients with sepsis-induced cardiac dysfunction did not increase to the normal level on day 10 (Fig. 2).

Correlation analysis. The following results were acquired through the correlation analysis (Fig. S1). NT-proBNP was positively correlated with H-FABP $(\mathrm{r}=0.403$; $\mathrm{P}<0.001)$ and cTnI $(\mathrm{r}=0.0 .573 ; \mathrm{P}<0.001)$ but was negatively correlated with $\mathrm{EF}(\mathrm{r}=-0.495 ; \mathrm{P}<0.001)$ and $\mathrm{E} / \mathrm{A}(\mathrm{r}=-0.195 ; \mathrm{P}=0.001)$. H-FABP was positively correlated with $\mathrm{cTnI}(\mathrm{r}=0.252 ; \mathrm{P}<0.001)$ but was negatively correlated with $\mathrm{EF}(\mathrm{r}=-0.202 ; \mathrm{P}=0.001)$ and $\mathrm{E} / \mathrm{A}$ $(\mathrm{r}=-0.141 ; \mathrm{P}=0.019)$.

ROC curve and binary logistic regression analyses for the 28-day mortality rate among patients with sepsis. Each ultrasound or laboratory indicator was analyzed and the occurrence of cardiac dysfunction was also determined. The results of the logistic regression analysis suggested that $\mathrm{CK}-\mathrm{MB}, \mathrm{A}, \mathrm{HF}$ and H-FABP were associated with the 28-day death rate of patients with sepsis $(\mathrm{P}<0.05)$. However, the differences in the AUC of CK-MB and A were not statistically significant, based on the ROC curve analysis $(\mathrm{P}>0.05)$. The threshold for H-FABP was
$35.7 \mathrm{ng} / \mathrm{ml}$, with a specificity and sensitivity of 53.00 and $76.60 \%$. An $\mathrm{HF}$ value $>0$ indicated that the patient had HF. Specificity and sensitivity values were 40.1 and $80.9 \%$ (Fig. 3; Table IX).

Diagnosis of cardiac dysfunction induced by sepsis. In the ROC curve analysis for NT-proBNP to identify cardiac dysfunction, the best threshold level was determined as $861.7 \mathrm{pg} / \mathrm{ml}$ (specificity, 89.22\%; sensitivity, 83.62\%; 95\% CI, 0.876, 0.945; AUC, 0.915). For EF, the best threshold was determined as $58.8 \%$ (specificity, $89.20 \%$; sensitivity, 62.10\%; 95\% CI, 0.698, 0.802; AUC, 0.753), and for H-FABP, the best threshold was determined as $30.3 \mathrm{ng} / \mathrm{ml}$ (specificity, 61.76\%; sensitivity, 76.27\%; 95\% CI, 0.615, 0.728; AUC, 0.673; Fig. 4).

\section{Discussion}

In the present study, alterations in echocardiography results were compared among patients with sepsis with or without cardiac dysfunction. These results suggested that patients with sepsis have an increased risk of cardiac insufficiency on days 7-10 after treatment. H-FABP was identified as a useful tool to predict the prognosis of patients with sepsis in the 
Table V. Comparison of N-terminal pro-brain natriuretic peptide (pg/ml) between sepsis with cardiac function group and sepsis without cardiac dysfunction group.

\begin{tabular}{cccr}
\hline Day & Sepsis with cardiac dysfunction & Sepsis without cardiac dysfunction & Z \\
\hline 1 & $5505(2189.0,8020.0)$ & $671(353.0,813.0)$ & -7.067 \\
3 & $2197.5(1317.0,6261.0)$ & $441(229.0,640.5)$ & -5.965 \\
7 & $2753.5(826.0,4976.0)$ & $279.5(119.6,300.5)$ & -6.285 \\
10 & $2044.1(589.8,4541.0)$ & $284.3(153.0,316.0)$ & -5.588 \\
\hline
\end{tabular}

Values are expressed as median (interquartile range).

Table VI. Comparison of echocardiographic indicators between control and sepsis groups.

\begin{tabular}{|c|c|c|c|c|c|c|}
\hline \multirow[b]{2}{*}{ Echocardiography } & \multirow[b]{2}{*}{ Control } & \multicolumn{4}{|c|}{ Sepsis } & \multirow[b]{2}{*}{$\chi^{2}$} \\
\hline & & 1st day & 3rd day & 7th day & 10th day & \\
\hline EDV (ml) & $117.62 \pm 30.11$ & $137.19 \pm 41.84$ & $130.01 \pm 22.31$ & $124.03 \pm 30.43^{\mathrm{a}}$ & $115.23 \pm 20.78^{\mathrm{a}}$ & 33.08 \\
\hline $\mathrm{ESV}(\mathrm{ml})$ & $42.55 \pm 16.07$ & $61.54 \pm 33.10$ & $55.91 \pm 17.30$ & $51.50 \pm 22.10$ & $44.88 \pm 9.701$ & 47.211 \\
\hline $\mathrm{SV}(\mathrm{ml})$ & $76.72 \pm 17.71$ & $79.15 \pm 28.55$ & $78.28 \pm 16.88$ & $77.03 \pm 17.46^{\mathrm{a}}$ & $70.35 \pm 15.66^{\mathrm{a}}$ & 8.571 \\
\hline $\mathrm{EF}(\%)$ & $64.76 \pm 7.09$ & $57.49 \pm 9.97$ & $60.32 \pm 7.38$ & $62.25 \pm 8.09^{\mathrm{a}}$ & $61.32 \pm 5.33^{\mathrm{a}}$ & 26.464 \\
\hline $\mathrm{CO}(1 / \mathrm{min})$ & $5.81 \pm 1.47$ & $7.10 \pm 2.81$ & $7.12 \pm 1.45$ & $6.65 \pm 2.07$ & $5.75 \pm 1.54^{\mathrm{a}}$ & 27.245 \\
\hline $\mathrm{E}(\mathrm{m} / \mathrm{sec})$ & $0.710 \pm 0.121$ & $0.749 \pm 0.100$ & $0.795 \pm 0.101$ & $0.700 \pm 0.146^{\mathrm{a}}$ & $0.815 \pm 0.265$ & 138.184 \\
\hline $\mathrm{A}(\mathrm{m} / \mathrm{sec})$ & $0.740 \pm 0.092$ & $0.954 \pm 0.196$ & $1.032 \pm 0.100$ & $1.026 \pm 0.177$ & $1.033 \pm 0.303$ & 113.440 \\
\hline $\mathrm{E} / \mathrm{A}$ & $0.959 \pm 0.050$ & $0.866 \pm 0.127$ & $0.875 \pm 0.118$ & $0.770 \pm 0.164$ & $0.879 \pm 0.289^{a}$ & 137.240 \\
\hline $\mathrm{S}(\mathrm{m} / \mathrm{sec})$ & $0.590 \pm 0.122$ & $0.413 \pm 0.058$ & $0.405 \pm 0.036$ & $0.401 \pm 0.079$ & $0.420 \pm 0.073$ & 80.389 \\
\hline $\mathrm{D}(\mathrm{m} / \mathrm{sec})$ & $0.440 \pm 0.113$ & $0.530 \pm 0.077$ & $0.522 \pm 0.072$ & $0.500 \pm 0.085$ & $0.476 \pm 0.772$ & 74.266 \\
\hline $\mathrm{S} / \mathrm{D}$ & $1.34 \pm 0.013$ & $0.78 \pm 0.07$ & $0.79 \pm 0.12$ & $0.81 \pm 0.14$ & $0.91 \pm 0.24$ & 105.339 \\
\hline
\end{tabular}

${ }^{\mathrm{a}} \mathrm{P}<0.05$ compared with the control group at baseline in the sepsis group. EDV, end-diastolic volume; ESV, end-systolic volume; SV, stroke volume; EF, left ventricle ejection fraction; $\mathrm{CO}$, cardiac output; E, mitral early diastolic peak velocity; A, mitral atrial systolic peak velocity; E/A, ratio of E/A; S, systolic pulmonary venous peak velocity; D, diastolic pulmonary venous peak velocity; S/D, ratio of S/D.

short-term. In addition, an H-FABP of $>30.3 \mathrm{ng} / \mathrm{ml}$ was able to determine the occurrence of cardiac dysfunction among patients with sepsis.

The present results suggest that CO, EF and SV decrease in patients with sepsis-induced cardiac dysfunction when compared with patients without cardiac dysfunction. In addition, the differences in EF on days 1 and 10 and in $\mathrm{CO}$ on days 1 and 7 were not statistically significant between these two groups. This indicates that heart function compensation occurs after active treatment in patients in an early stage of sepsis, and this is associated with early cardiac sepsis through a self-regulatory mechanism. This is referred to as the Frank-Starling mechanism, which is a filling force mechanism based on a positive association between the distension of the ventricular chamber and its force of ejection $(23,24)$. Furthermore, the increase in venous return dilates the ventricle(s), stretches the myocardium and increases the contractility of the muscle, efficiently regulating the stroke volume. Furthermore, the sympathetic-adrenal axis is excited to release excessive catecholamines, and the secretion of renin-angiotensin is increased, along with enhanced heart pumping function and myocardial contractility (25), finally attaining normal or greater cardiac output (26). Patients with sepsis-induced cardiac insufficiency receive active treatment to maintain the normal $\mathrm{CO}$ level and retain systemic organ perfusion, but their cardiac functions are not evidently enhanced. When heart function is not persistently improved, the disease in patients with sepsis is aggravated, they gradually enter the refractory phase and the systolic residual blood volume in the left ventricle and peripheral resistance decrease, while EF returns to the normal level or increases. The present study revealed that the E/A among patients with sepsis-induced cardiac dysfunction was minimized on day 7 and had not returned to the normal level on day 10 , suggesting that the diastolic function of the left ventricle in patients with sepsis transitioned on day 7 and the recovery of diastolic function may be slow when compared with that of systolic function. Parker et al (27) examined the results of radionuclide scanning of 20 patients with septic shock and discovered that cardiac function was temporarily lowered in 13 patients with normal initial myocardial function. Of note, the myocardial function recovery pattern on days 7-10 was of crucial importance to survival. Thus, the cardiac function recovery time is expected to be on days 7-10 for patients with sepsis, which is associated with the prognosis of these patients. 


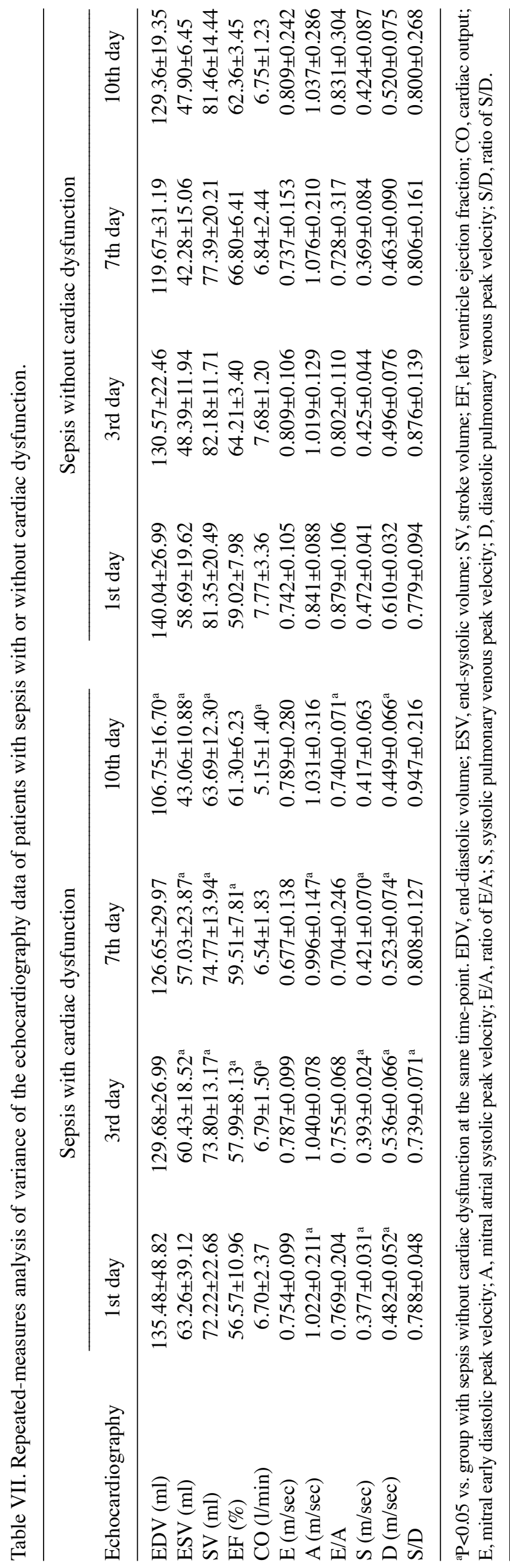

NT-proBNP has become a vital indicator to assess changes in cardiac function. In addition, NT-proBNP is a critical factor in the evaluation and serological diagnosis according to global HF guidelines (13). Khoury et al (28) suggested that NT-proBNP may serve as an independent factor to predict the short-term or long-term death rate of inpatients with sepsis. Lin et al (29) performed a study on 21 pediatric patients with sepsis and reported that an NT-proBNP of $>1,268 \mathrm{ng} / \mathrm{l}$ may be used to predict the incidence of cardiac insufficiency in such patients. Furthermore, NT-proBNP may be an important reference for the diagnosis of sepsis in patients with cardiac insufficiency. FABP is a cytosolic protein that has a vital role in the metabolism, transport and uptake of fatty acids (30). Typically, H-FABP is specific for myocardial cells and is detected in serum in the case of myocardial damage due to different reasons (31). In addition, H-FABP may predict even small amounts of myocardial damage $(32,33)$. These present findings suggest that $\mathrm{H}-\mathrm{FABP}>35.7 \mathrm{ng} / \mathrm{ml}$ may predict a dismal prognosis for patients with sepsis in the short term, which is consistent with the results reported by other studies. performed a study on 295 patients with sepsis and reported that H-FABP may serve as an independent factor to predict the 28-day death rate and organ dysfunction in such patients. Jo et al (34) investigated 99 patients with sepsis and reported that H-FABP Chen and $\mathrm{Li}(18)>40 \mathrm{ng} / \mathrm{ml}$ was an independent factor that predicted the death of patients with sepsis, and H-FABP $>40 \mathrm{ng} / \mathrm{ml}$ also increased the risk of death by 5.57 -fold at the 28-day follow-up. Thus, H-FABP is closely correlated with the severity of sepsis, which is a risk factor for a dismal prognosis of patients with sepsis $(17,18)$. Fan et al (35) reported that the serum H-FABP levels in mice with sepsis-induced myocardial injury evidently increased compared with those in mice with no myocardial injury. Furthermore, the H-FABP level decreased as cardiac function improved. However, no existing study has been performed to examine the association between sepsis-induced cardiac dysfunction and H-FABP in humans.

According to the present results, H-FABP exhibited a positive correlation with NT-proBNP $(r=0.403 ; \mathrm{P}<0.001)$ and $\mathrm{cTnI}(\mathrm{r}=0.252 ; \mathrm{P}<0.001)$. Furthermore, the H-FABP, cTnI and NT-proBNP levels in patients with sepsis-induced cardiac dysfunction were increased relative to those in patients with sepsis without cardiac dysfunction. These results suggest that patients with sepsis and severe myocardial damage have an increased risk of cardiac insufficiency. On the other hand, the present results indicate that the H-FABP, cTnI and NT-proBNP levels in patients with sepsis and cardiac insufficiency peaked on the first day. Subsequently, the H-FABP gradually decreased, regardless of the presence or absence of cardiac dysfunction. On the 10th day, the H-FABP in sepsis patients without HF evidently increased when compared with that in patients without HF, suggesting that various changes in heart function occurred in patients with sepsis on days 7-10. The cTnI and H-FABP levels in patients with sepsis were higher on day 10 of hospitalization, which indicates that a longer time is required to recover the damage to myocardial cells following myocardial injury in patients with sepsis, regardless of the improved heart function.

Patients with sepsis and cardiac insufficiency have a poor response to liquid volume (36). Hence, increased fluid resuscitation is required during the retreatment process, as 
Table VIII. Echocardiography repeated measures analysis of variance statistical results.

\begin{tabular}{|c|c|c|c|c|c|c|}
\hline \multirow[b]{2}{*}{ Echocardiography } & \multicolumn{2}{|c|}{ Time } & \multicolumn{2}{|c|}{ Time $\mathrm{x}$ group } & \multicolumn{2}{|c|}{ Group } \\
\hline & $\mathrm{F}$ & P-value & $\mathrm{F}$ & P-value & $\mathrm{F}$ & P-value \\
\hline EDV (ml) & 7.974 & $<0.001$ & 4.263 & 0.013 & 1.444 & 0.233 \\
\hline $\mathrm{ESV}(\mathrm{ml})$ & 8.306 & $<0.001$ & 3.615 & 0.031 & 4.663 & 0.034 \\
\hline $\mathrm{SV}(\mathrm{ml})$ & 5.511 & 0.002 & 1.246 & 0.294 & 11.852 & 0.001 \\
\hline $\mathrm{EF}(\%)$ & 8.512 & $<0.001$ & 2.365 & 0.082 & 17.110 & $<0.001$ \\
\hline $\mathrm{CO}(1 / \mathrm{min})$ & 9.515 & $<0.001$ & 1.861 & 0.142 & 9.951 & 0.002 \\
\hline $\mathrm{E}(\mathrm{m} / \mathrm{sec})$ & 6.792 & 0.002 & 0.813 & 0.433 & 0.488 & 0.487 \\
\hline $\mathrm{A}(\mathrm{m} / \mathrm{sec})$ & 5.917 & 0.003 & 6.936 & 0.001 & 0.956 & 0.331 \\
\hline $\mathrm{E} / \mathrm{A}$ & 8.438 & 0.001 & 0.265 & 0.693 & 0.028 & 0.868 \\
\hline $\mathrm{S}(\mathrm{m} / \mathrm{sec})$ & 4.488 & 0.007 & 23.142 & $<0.001$ & 7.242 & 0.009 \\
\hline $\mathrm{D}(\mathrm{m} / \mathrm{sec})$ & 12.145 & $<0.001$ & 32.123 & $<0.001$ & 11.185 & 0.001 \\
\hline $\mathrm{S} / \mathrm{D}$ & 8.102 & 0.001 & 7.927 & 0.001 & 0.102 & 0.750 \\
\hline
\end{tabular}

Time: Regardless of grouping, comparison of different measurement times; Time x Group: Comparison of time and group interaction; Group: Regardless of measurement time, comparison between different groups. EDV, end-diastolic volume; ESV, end-systolic volume; SV, stroke volume; EF, left ventricle ejection fraction; $\mathrm{CO}$, cardiac output; E, mitral early diastolic peak velocity; A, mitral atrial systolic peak velocity; E/A, ratio of E/A; S, systolic pulmonary venous peak velocity; D, diastolic pulmonary venous peak velocity; S/D, ratio of S/D.
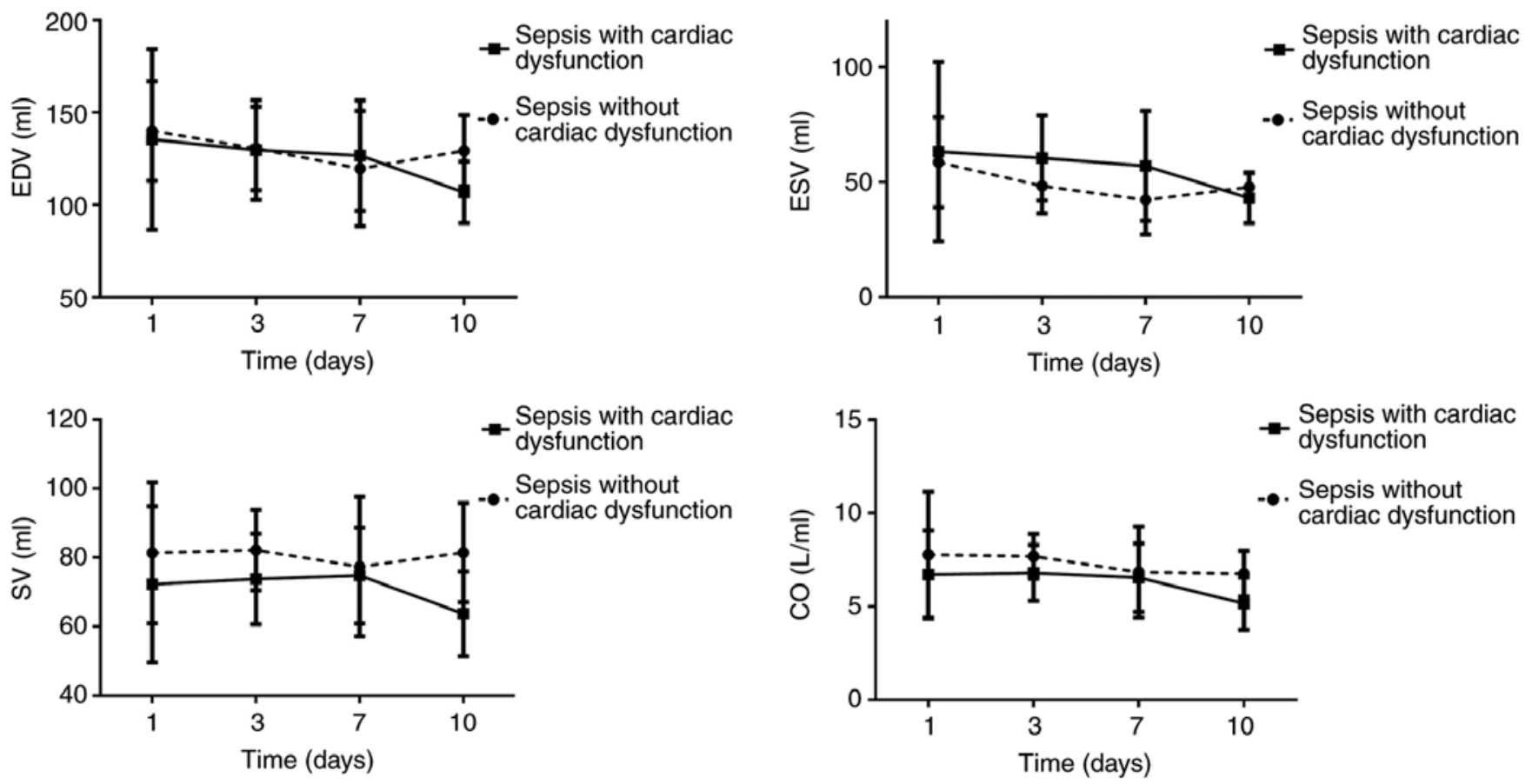

Sepsis with cardiac dysfunction
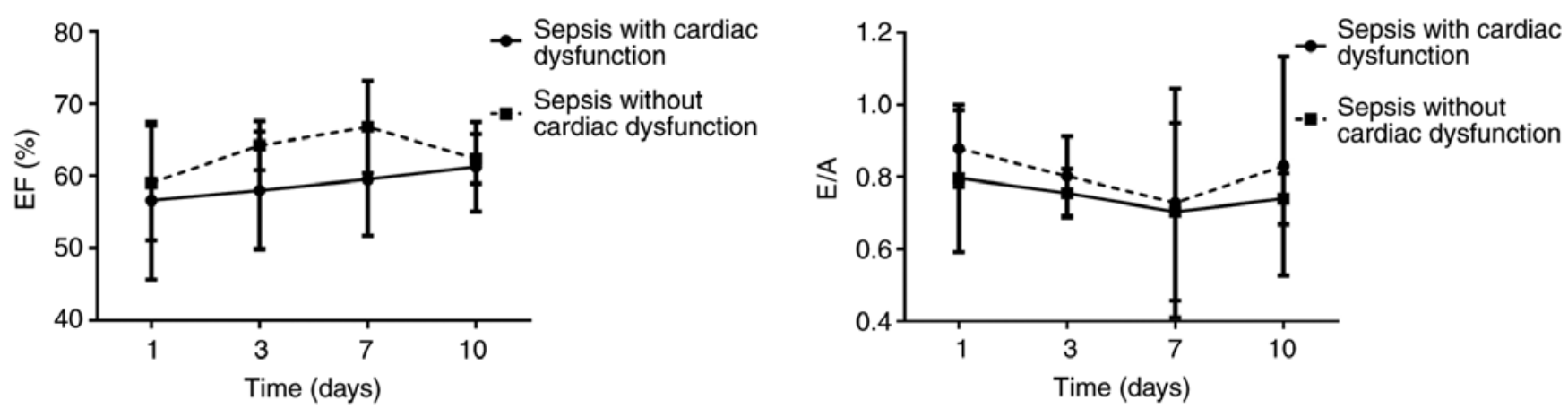

Figure 2. Changes in ultrasound indexes EDV, ESV, SV, CO, EF and E/A over time. EDV, end-diastolic volume; ESV, end-systolic volume; SV, stroke volume; $\mathrm{EF}$, left ventricle ejection fraction; $\mathrm{CO}$, cardiac output; $\mathrm{E}$, mitral early diastolic peak velocity; A, mitral atrial systolic peak velocity; E/A, ratio of E/A. 


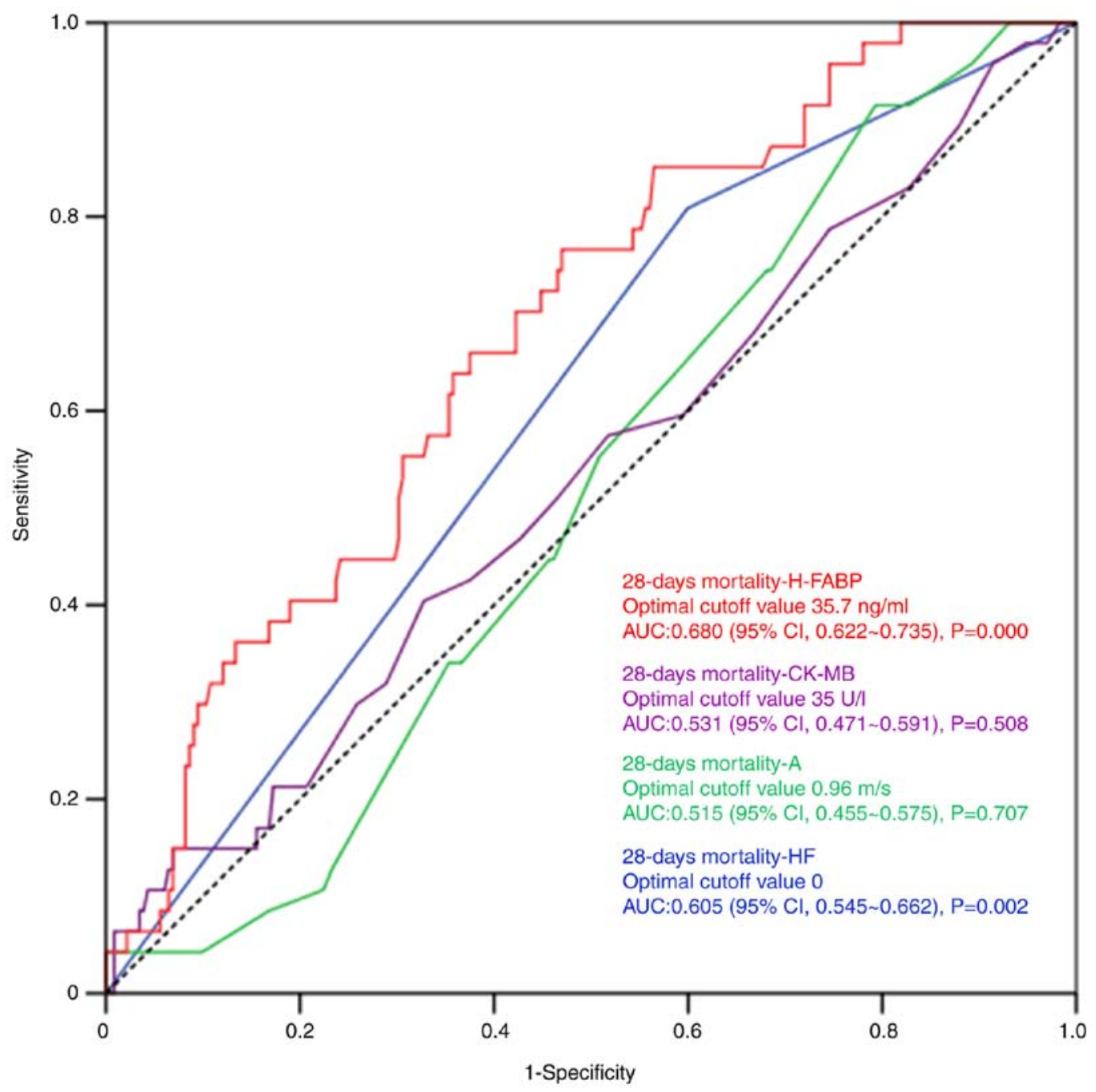

Figure 3. Receiver operating characteristic curves for independent predictors of 28-day mortality. AUC, area under the curve; H-FABP, heart-type fatty acid-binding protein; CK-MB, creatine kinase-MB; s, second; A, mitral atrial systolic peak velocity; HF, heart failure.

well as the use of vasoactive drugs. Therefore, patients with sepsis and cardiac insufficiency have a heavy volume load, which increases the concentration of NT-proBNP in the blood. The present study also revealed that inflammatory indicators were higher in the sepsis with cardiac dysfunction group than in the sepsis with normal heart function group, indicating that sepsis with heart dysfunction has a more serious inflammatory response and that inflammatory cells and mediators directly or indirectly induce cardiac toxicity, causing NT-proBNP to increase $(26,37)$. A study performed with the use of myocardial radionuclides in patients with septic shock revealed that the 7- to 10-day repair time of myocardial injury is important for the prognosis of patients with sepsis due to myocardial injury caused by septic shock. This indicates that the recovery time for myocardial injury in patients with sepsis may be within 7-10 days. Therefore, NT-proBNP may still be high in patients with sepsis and cardiac insufficiency at 10 days.

The alterations in cardiac markers and the echocardiography results of patients with sepsis suggest that such patients have an increased risk of cardiac insufficiency on days 7-10 of hospitalization. Lorts et al (38) suggested that patients with sepsis have the highest risk of cardiac dysfunction on days 5-7 of hospitalization.
Therefore, day 7 of hospitalization is a vital time-point to examine the changes in heart function in patients with sepsis.

According to the present results, $\sim 58.8 \%$ of patients with sepsis $(n=47)$ suffered from diastolic dysfunction in the left ventricle, while only 3 (3.8\%) had systolic dysfunction in the ventricle and $10(12.5 \%)$ had diastolic and systolic dysfunction in the left ventricle. This suggests that patients with sepsis have a higher risk of diastolic dysfunction than of systolic dysfunction. Furthermore, studies suggested that the serum H-FABP concentration in patients with sepsis is significantly higher than that in healthy subjects. Regardless of the type of cardiac dysfunction that occurred in patients with sepsis, the serum H-FABP concentration at various time-points was higher in patients with sepsis with cardiac dysfunction than in patients with sepsis without cardiac dysfunction. The correlation analysis revealed that H-FABP was negatively correlated with $\mathrm{EF}(\mathrm{r}=-0.202$, $\mathrm{P}=0.001)$ and $\mathrm{E} / \mathrm{A}(\mathrm{r}=-0.141, \mathrm{P}=0.019)$, further indicating that the level of H-FABP increased in the case of either systolic dysfunction or diastolic dysfunction. These results suggest that the serum levels of H-FABP may be used to assess dysfunction in the left ventricle in patients with sepsis.

Kandil et al (39) investigated 49 patients with sepsis and discovered that the BNP content in those patients was 
Table IX. Binary logistic regression analysis for parameters affecting 28-day mortality.

\begin{tabular}{lcccccc}
\hline Variable & $\mathrm{b}$ & $\mathrm{SE}$ & Wald $\chi^{2}$ & P-value & OR & $95 \%$ CI \\
\hline A $(\mathrm{m} / \mathrm{sec})$ & 1.784 & 0.859 & 4.317 & 0.038 & 5.957 & $(1.106,32.069)$ \\
PCT $(\mathrm{ng} / \mathrm{ml})$ & -0.280 & 0.019 & 2.282 & 0.131 & 0.972 & $(0.937,1.008)$ \\
CK-MB $(\mathrm{U} / \mathrm{l})$ & 0.016 & 0.008 & 4.036 & 0.045 & 1.016 & $(1.000,1.032)$ \\
H-FABP $(\mathrm{ng} / \mathrm{ml})$ & 0.063 & 0.015 & 17.272 & $<0.001$ & 1.065 & $(1.034,1.097)$ \\
NT-proBNP $(\mathrm{pg} / \mathrm{ml})$ & 0.000 & 0.000 & 3.647 & 0.056 & 0.999 & $(0.999,1.000)$ \\
HF & 1.090 & 0.445 & 5.999 & 0.014 & 2.975 & $(1.243,7.120)$ \\
Constant & -6.528 & 1.226 & 28.349 & $<0.001$ & 0.001 & - \\
\hline
\end{tabular}

The constant was calculated via logistic regression by SPSS. A, mitral atrial systolic peak velocity; PCT, procalcitonin; CK-MB, creatine kinase-MB; H-FABP, heart-type fatty acid-binding protein; NT-proBNP, N-terminal pro-brain natriuretic peptide; HF, heart failure. b, regression coefficient; SE, standard error; Wald $\chi^{2}, \chi^{2}$ value of Wald statistic; OR, odds ratio; 95\% CI, 95\% confidence interval.

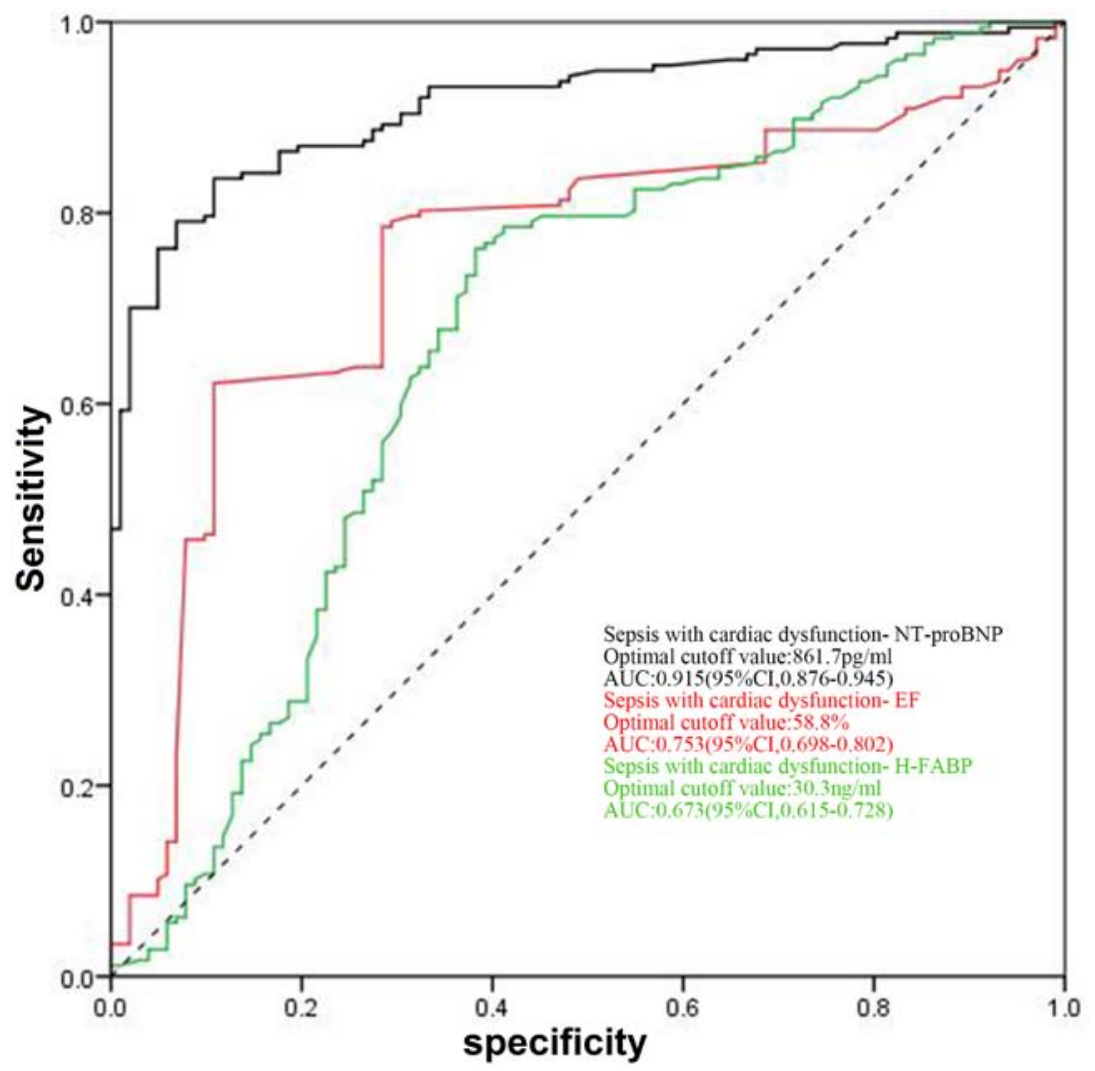

Figure 4. Receiver operating characteristic curves for NT-proBNP, EF and H-FABP levels for the diagnosis of cardiac dysfunction in sepsis. EF, ejection fraction; H-FABP, heart-type fatty acid-binding protein; NT-proBNP, N-terminal pro-brain natriuretic peptide.

apparently increased when compared with that in patients with early sepsis with positive BNP, indicating that the BNP level in patients with sepsis increases during circulatory dysfunction. Furthermore, Landesberg et al (40) investigated 256 patients with septic shock and severe sepsis and discovered that NT-proBNP and high-sensitive troponin T (hs-TnT) were markedly increased in groups of patients with sepsis that survived or died, with data in the latter group being significantly higher compared with former group. In addition, relative to patients with normal diastolic and systolic functions, patients with an e'-wave of $<8 \mathrm{~cm} / \mathrm{sec}, \mathrm{EF} \leq 50 \%$ or e'-wave $<8 \mathrm{~cm} / \mathrm{sec}$ and $\mathrm{EF} \leq 50 \%$ combined had higher levels of NT-proBNP and
hs-TnT. Furthermore, the cTnI and NT-proBNP levels were apparently increased in patients with sepsis-induced cardiac dysfunction compared with those in patients without cardiac dysfunction. The results of the ROC curve analysis for the diagnosis of sepsis-induced cardiac dysfunction revealed that HF may be considered to be present in patients with sepsis and NT-proBNP $>861.7 \mathrm{pg} / \mathrm{ml}$. The specificity, sensitivity and AUC (with 95\% CI) were 89.22, 83.62\% and 0.915 (0.876, $0.945)$, respectively. In addition, the specificity, sensitivity and AUC (with 95\% CI) for the diagnosis of cardiac dysfunction in patients with sepsis and $\mathrm{EF} \leq 58.8 \%$ were $89.20,62.10 \%$ and $0.753(0.698,0.826)$, respectively. EF and NT-proBNP 
have higher specificity but lower sensitivity in the diagnosis of sepsis-induced cardiac dysfunction. Thus, these results have clinical significance in the detection of cardiac dysfunction in patients with sepsis. A diagnosis of sepsis-induced cardiac dysfunction may be indicated if H-FABP $>30.3 \mathrm{ng} / \mathrm{ml}$, and the specificity, sensitivity and AUC (with 95\% CI) were 61.7, $76.27 \%$ and $0.673(0.615,0.728)$, respectively. The specificity and sensitivity of H-FABP in the diagnosis of sepsis-induced cardiac dysfunction remain poor, which may be ascribed to the increased fat catabolism and glycogen at sepsis onset. The free fatty acid levels increased, which may directly result in elevated H-FABP levels (41). In addition, H-FABP is mainly excreted via renal excretion (42). As a result, in the case of decreased renal function associated with sepsis, the H-FABP level was elevated. Thus, patient conditions should be comprehensively assessed when H-FABP is applied in the diagnosis of cardiac insufficiency for patients with sepsis.

Studies have indicated that the occurrence of HF is a risk factor for 28-day mortality in patients with sepsis, with an odds ratio of 2.975 (95\% CI: $1.243,7.120)$, indicating that patients with cardiac insufficiency have a poor short-term prognosis. This may be because early fluid resuscitation is recommended for sepsis treatment and patients with cardiac insufficiency have poorer fluid response, heavier fluid load and receive more vasoactive drugs, but systemic tissue perfusion may not significantly improve during treatment. Furthermore, organ function is continuously impaired and even fails, which in turn causes multiple organ dysfunction syndrome, making the treatment of patients with sepsis more difficult and worsening the prognosis. However, studies have suggested that, although the mortality of patients with sepsis and cardiac insufficiency is higher than that of normal cardiac function, the difference was not statistically significant and this is considered to be associated with the small sample size of the present study.

Acute systolic HF is inherent in patients with sepsis, but diastolic HF almost never occurs unless HF has occurred in the past. Of note, in the present study, the EF values were normal, while the E/A values were abnormal in the patients with sepsis and HF, and in those with sepsis and no HF, but the difference was not significant. According to the Evaluation of Left Ventricular Diastolic Function by Echocardiography guidelines from the American Society of Echocardiography and the European Association of Cardiovascular Imaging (43), the E peak gradually decreases with age, while the A peak gradually increases with age and the E/A ratio gradually decreases. The Echocardiography Examination Guideline for patients of Chinese ethnicities in 2018 also revealed similar results (44), which may be ascribed to the normal aging-induced increase in left ventricular wall stiffness, the reduction in myocardial elongation length and the weakened or non-weakened early diastolic aspiration. As a result, the heart filling pressure is upregulated, ventricular diastolic function is reduced, the ventricular isovolumic relaxation time is extended and the $\mathrm{E}$ peak decreases. Accordingly, to maintain the normal level of cardiac output, the late ventricular diastolic filling volume increases and the A peak becomes elevated. In addition, the cause of such serial changes may be CAD or other subclinical diseases, especially in elderly subjects with sub-health status. Therefore, the elderly cardiac function pattern may manifest as mild diastolic dysfunction when compared with that of young patients. Furthermore, the guidelines (43) suggested that E/A $\geq 0.8$, E/ early diastolic mitral annular velocity $\left(\mathrm{e}^{\prime}\right)<10$, peak tricuspid regurgitation $(\mathrm{TR})$ velocity $(\mathrm{m} / \mathrm{sec})<2.8$ and left atrial volume index at the normal range may possibly indicate normal ventricular diastolic function. The subjects enrolled in the present study were older but had little healthcare-associated knowledge, and they did not undergo regular physical examinations. Thus, it was not possible to definitely exclude potential CADs. $\mathrm{E} / \mathrm{A}<1$ was obtained in the sepsis with normal cardiac function group, which may be associated with aggressive liquid resuscitation and the use of anti-infective agents during the sepsis treatment process, in addition to the age factor. Furthermore, 7-10 days of anti-infective treatment was recommended in the Sepsis Diagnosis and Treatment Guideline for patients with sepsis or septic shock, which is similar to the result that 7-10 days is the transition point of cardiac function in patients with sepsis (1). This is considered to be associated with the alleviation or elimination of inflammation suppression or injury on myocardial cells, thereby achieving an effective anti-infective treatment. Similarly, certain studies reported that patients with sepsis may develop simple diastolic dysfunction (45); that is, patients have a normal EF while $\mathrm{E} / \mathrm{A}<1$. At the same time, the physical examination results suggest that $0.8<\mathrm{E} /$ $\mathrm{A}<1$. Accordingly, patients with sepsis may have a normal $\mathrm{EF}$ value when $\mathrm{E} / \mathrm{A}<1$.

Certain limitations of the present study should be pointed out. First, the sample size of the present study was small due to its single-center nature. Furthermore, the patients with sepsis had unstable vital signs and were critically ill upon admission. Hence, the patients always need emergent treatment and it was difficult to collect heart ultrasound data prior to treatment. Furthermore, the alterations in cardiac markers and heart ultrasound findings in patients with sepsis were monitored and more precise and creditable results were obtained when compared to those acquired from prior studies, which pertain to the cardiac function of patients with sepsis. In addition, prior studies have not sufficiently focused on sepsis-induced cardiac dysfunction and H-FABP in patients. Instead, these studies mainly focused on disease severity and patient prognosis.

In conclusion, patients with sepsis have an increased risk of cardiac insufficiency on days 7-10. H-FABP may serve as an indicator to estimate the prognosis of patients with sepsis in the short term, which is of certain significance in the diagnosis of sepsis-induced cardiac dysfunction.

\section{Acknowledgements}

Not applicable.

\section{Funding}

This work was supported by the Science and Technology Development Plan Project of the Xinjiang Production and Construction Corps, China (grant no. KC0038).

\section{Availability of data and materials}

The datasets used and/or analyzed during the current study are available from the corresponding author on reasonable request. 


\section{Authors' contributions}

GW screened the cases and performed statistical analysis. PT performed laboratory analyses of the patient samples. XY performed cardiac echocardiography. QC designed the study and majorly contributed to the writing of the manuscript. All authors read and approved the final manuscript.

\section{Ethics approval and consent to participate}

The current study protocol was approved by the Ethics Committee of the First Affiliated Hospital of Medical College, Shihezi University (no. 250457) and written informed consent was obtained from each participant.

\section{Patient consent for publication}

Not applicable.

\section{Competing interests}

The authors declare that they have no competing interests.

\section{References}

1. Rhodes A, Evans LE, Alhazzani W, Levy MM, Antonelli M, Ferrer R, Kumar A, Sevransky JE, Sprung CL, Nunnally ME, et al: Surviving sepsis campaign: International guidelines for management of sepsis and septic shock: 2016. Intensive Care Med 43: 304-377, 2017.

2. Shankar-Hari M, Phillips GS, Levy ML, Seymour CW, Liu VX Deutschman CS, Angus DC, Rubenfeld GD, Singer M and Sepsis Definitions Task Force: Developing a new definition and assessing new clinical criteria for septic shock: For the third international consensus definitions for sepsis and septic shock (Sepsis-3). JAMA 315: 775-787, 2016.

3. Zhou J, Qian C, Zhao M, Yu X, Kang Y, Ma X, Ai Y, Xu Y, Liu D, An Y, et al: Epidemiology and outcome of severe sepsis and septic shock in intensive care units in mainland China. PLoS One 9: e107181, 2014.

4. Zanotti-Cavazzoni SL and Hollenberg SM: Cardiac dysfunction in severe sepsis and septic shock. Curr Opin Crit Care 15: 392-397, 2009.

5. Chong J, Dumont T, Francis-Frank L and Balaan M: Sepsis and septic shock: A review. Crit Care Nurs Q 38: 111-120, 2015.

6. Sanfilippo F, Corredor C, Fletcher N, Landesberg G, Benedetto U, Foex P and Cecconi M: Erratum to: Diastolic dysfunction and mortality in septic patients: A systematic review and meta-analysis. Intensive Care Med 41: 1178-1179, 2015.

7. Brennan LM, Widder MW, McAleer MK, Mayo MW, Greis AP and van der Schalie WH: Preparation and testing of impedance-based fluidic biochips with RTgill-W1 cells for rapid evaluation of drinking water samples for toxicity. J Vis Exp, 2016

8. Werdan K, Schmidt H, Ebelt H, Zorn-Pauly K, Koidl B, Hoke RS, Heinroth K and Müller-Werdan U: Impaired regulation of cardiac function in sepsis, SIRS, and MODS. Can J Physiol Pharmacol 87: 266-274, 2009.

9. Rudski LG, Lai WW, Afilalo J, Hua L, Handschumacher MD, Chandrasekaran K, Solomon SD, Louie EK and Schiller NB: Guidelines for the echocardiographic assessment of the right heart in adults: A report from the American society of echocardiography endorsed by the European association of echocardiography, a registered branch of the European society of cardiology, and the canadian society of echocardiography. J Am Soc Echocardiogr 23: 685-713, 2010.

10. Group CMAUMBE: Chinese adult echocardiography examination and measurement guide. Chin J Ultrasonography 25 645-666, 2016 (In Chinese).

11. Pulido JN, Afessa B, Masaki M, Yuasa T, Gillespie S, Herasevich V, Brown DR and Oh JK: Frequency and clinical spectrum of myocardial dysfunction in severe sepsis and septic shock. Mayo Clin Proc 87: 620-628, 2012.
12. Sato R, Kuriyama A, Takada T, Nasu M and Luthe SK: Prevalence and risk factors of sepsis-induced cardiomyopathy: A retrospective cohort study. Medicine (Baltimore) 95: e5031, 2016.

13. Yancy CW, Jessup M, Bozkurt B, Butler J, Casey DE Jr, Colvin MM, Drazner MH, Filippatos GS, Fonarow GC, Givertz MM, et al: 2017 ACC/AHA/HFSA focused update of the 2013 ACCF/AHA guideline for the management of heart failure: A report of the American college of cardiology/American heart association task force on clinical practice guidelines and the heart failure society of America. J Am Coll Cardiol 70: 776-803, 2017.

14. Kakihana Y, Ito T, Nakahara M, Yamaguchi K and Yasuda T: Sepsis-induced myocardial dysfunction: Pathophysiology and management. J Intensive Care 4: 22, 2016.

15. Sato R and Nasu M: A review of sepsis-induced cardiomyopathy. J Intensive Care 3: 48, 2015.

16. Luo JQ, LI JC and Long ZH: The clinical application of heart-fatty acid binding protein in AMI early diagnosis. Chin J Clin Pathologist 1: 22-25, 2016 (In Chinese).

17. Zhang ZC, Dai HW, Yu YH, Yang JD and Hu CB: Usefulness of heart-type fatty acid-binding protein in patients with severe sepsis. J Crit Care 27: e413-e415.e418, 2012.

18. Chen YX and Li CS: The prognostic and risk-stratified value of heart-type fatty acid-binding protein in septic patients in the emergency department. J Crit Care 29: 512-516, 2014.

19. You HJ, Kim K, Lee JH, Rhee JE, Lee JH, Kang KW, Rim KP, Hwang SS and Park HM: Heart-type fatty acid-binding protein as a prognostic factor in patients with severe sepsis and septic shock. Am J Emerg Med 30: 1749-1755, 2012.

20. Singer M, Deutschman CS, Seymour CW, Shankar-Hari M, Annane D, Bauer M, Bellomo R, Bernard GR, Chiche JD, Coopersmith CM, et al: The third international consensus definitions for sepsis and septic shock (Sepsis-3). JAMA 315: 801-810, 2016.

21. Nagueh SF, Smiseth OA, Appleton CP, Byrd BF III, Dokainish H, Edvardsen T, Flachskampf FA, Gillebert TC, Klein AL, Lancellotti P, et al: Recommendations for the evaluation of left ventricular diastolic function by echocardiography: An update from the American society of echocardiography and the European association of cardiovascular imaging. J Am Soc Echocardiogr 29: 277-314, 2016.

22. Knaus WA, Draper EA, Wagner DP and Zimmerman JE: APACHE II: A severity of disease classification system. Crit Care Med 13: 818-829, 1985.

23. Holubarsch C, Ruf T, Goldstein DJ, Ashton RC, Nickl W, Pieske B, Pioch K, Ludemann J, Wiesner S, Hasenfuss G, et al: Existence of the Frank-Starling mechanism in the failing human heart. Investigations on the organ, tissue, and sarcomere levels. Circulation 94: 683-689, 1996.

24. Shiels HA and White E: The frank-starling mechanism in vertebrate cardiac myocytes. J Exp Biol 211: 2005-2013, 2008.

25. Redfors B, Shao Y and Omerovic E: Male rats are more prone to develop Takotsubo-like cardiac dysfunction in response to high-dose catecholamine than are female rats. Eur Heart J 34: P5047, 2013.

26. Chaui-Berlinck JG and Monteiro LHA: Frank-Starling mechanism and short-term adjustment of cardiac flow. J Exp Biol 220: 4391-4398, 2017.

27. Parker MM, Shelhamer JH, Bacharach SL, Green MV, Natanson C, Frederick TM, Damske BA and Parrillo JE: Profound but reversible myocardial depression in patients with septic shock. Ann Intern Med 100: 483-490, 1984.

28. Khoury J, Arow M, Elias A, Makhoul BF, Berger G, Kaplan M, Mashiach T, Ismael-Badarneh R, Aronson D and Azzam ZS: The prognostic value of brain natriuretic peptide (BNP) in non-cardiac patients with sepsis, ultra-long follow-up. J Crit Care 42: 117-122, 2017.

29. Lin CW, Tang W, Wen F, Chen JJ, Zeng XL and Chen ZG: Diagnostic accuracy of NT-ProBNP for heart failure with sepsis in patients younger than 18 years. PLoS One 11: e0147930, 2016.

30. Storch J and Thumser AE: The fatty acid transport function of fatty acid-binding proteins. Biochim Biophys Acta 1486: 28-44, 2000 .

31. Smathers RL and Petersen DR: The human fatty acid-binding protein family: Evolutionary divergences and functions. Hum Genomics 5: 170-191, 2011.

32. Wang Y, Guo Z and Huang L: Value of different biochemical markers in early diagnosis of acute myocardial infarction. Nan Fang Yi Ke Da Xue Xue Bao 34: 1347-1350, 2014 (In Chinese). 
33. Cubranic Z, Madzar Z, Matijevic S, Dvornik S, Fisic E, Tomulic V, Kunisek J, Laskarin G, Kardum I and Zaputovic L: Diagnostic accuracy of heart fatty acid binding protein (H-FABP) and glycogen phosphorylase isoenzyme BB (GPBB) in diagnosis of acute myocardial infarction in patients with acute coronary syndrome. Biochem Med (Zagreb) 22: 225-236, 2012.

34. Jo YH, Kim K, Lee JH, Rhee JE, Lee JH, Kang KW, Rim KP, Hwang SS and Park HM: Heart-type fatty acid-binding protein as a prognostic factor in patients with severe sepsis and septic shock. Am J Emerg Med 30: 1749-1755, 2012.

35. Fan TT, Feng XY, Yang YZ, Gao F and Liu Q: Downregulation of PI3K-g in a mouse model of sepsis-induced myocardial dysfunction. Cytokine 96: 208-216, 2017.

36. Hartemink KJ, Twisk JW and Groeneveld AB: High circulating $\mathrm{N}$-terminal pro-B-type natriuretic peptide is associated with greater systolic cardiac dysfunction and nonresponsiveness to fluids in septic vs nonseptic critically ill patients. J Crit Care 26: e101-e108, 2011.

37. Tomaru Ki K, Arai M, Yokoyama T, Aihara Y, Sekiguchi Ki K, Tanaka T, Nagai R and Kurabayashi M: Transcriptional activation of the BNP gene by lipopolysaccharide is mediated through GATA elements in neonatal rat cardiac myocytes. J Mol Cell Cardiol 34: 649-659, 2002

38. Lorts A, Burroughs T and Shanley TP: Elucidating the role of reversible protein phosphorylation in sepsis-induced myocardial dysfunction. Shock 32: 49-54, 2009.

39. Kandil E, Burack J, Sawas A, Bibawy H, Schwartzman A, Zenilman ME and Bluth MH: B-type natriuretic peptide: A biomarker for the diagnosis and risk stratification of patients with septic shock. Arch Surg 143: 242-246, 2008.

40. Landesberg G, Levin PD, Gilon D, Goodman S, Georgieva M, Weissman C, Jaffe AS, Sprung CL and Barak V: Myocardial dysfunction in severe sepsis and septic shock: No correlation with inflammatory cytokines in real-life clinical setting. Chest 148: 93-102, 2015.
41. Yan GT, Lin J, Hao XH, Xue H, Zhang $\mathrm{K}$ and Wang LH: Heart-type fatty acid-binding protein is a useful marker for organ dysfunction and leptin alleviates sepsis-induced organ injuries by restraining its tissue levels. Eur J Pharmacol 616: 244-250, 2009.

42. Tanaka T, Hirota Y, Sohmiya K, Nishimura S and Kawamura K: Serum and urinary human heart fatty acid-binding protein in acute myocardial infarction. Clin Biochem 24: 195-201, 1991.

43. Nagueh SF, Smiseth OA, Appleton CP, Byrd BF III, Dokainish H, Edvardsen T, Flachskampf FA, Gillebert TC, Klein AL, Lancellotti P, et al: Recommendations for the evaluation of left ventricular diastolic function by echocardiography: An update from the American society of echocardiography and the European association of cardiovascular imaging. Eur Heart J Cardiovasc Imaging 17: 1321-1360, 2016.

44. Echocardiography Group of Ultrasound Medicine Branch of Chinese Medical Association: Guide for Chinese adult echocardiography examination and measurement. Chin J Ultrasonogr 25: 645-666, 2016.

45. Landesberg G, Gilon D, Meroz Y, Georgieva M, Levin PD, Goodman S, Avidan A, Beeri R, Weissman C, Jaffe AS and Sprung CL: Diastolic dysfunction and mortality in severe sepsis and septic shock. Eur Heart J 33: 895-903, 2012.

This work is licensed under a Creative Commons Attribution-NonCommercial-NoDerivatives 4.0 International (CC BY-NC-ND 4.0) License. 